\title{
Cloud processing, cloud evaporation and Angström exponent
}

\author{
G.-J. Roelofs and V. Kamphuis \\ Institute for Marine and Atmospheric Research Utrecht (IMAU), Utrecht University, Princetonplein 5, 3584 CC Utrecht, \\ The Netherlands
}

Received: 19 May 2008 - Published in Atmos. Chem. Phys. Discuss.: 4 July 2008

Revised: 2 December 2008 - Accepted: 2 December 2008 - Published: 7 January 2009

\begin{abstract}
With a cloud parcel model we investigate how cloud processing and cloud evaporation modify the size distribution and the Angström exponent of an aerosol population. Our study provides a new explanation for the observed variability of the aerosol optical thickness and Angström exponent in the vicinity of clouds. Cloud processing causes a decrease of aerosol particle concentrations, relatively most efficiently in the coarse mode, and reduces the relative dispersion of the aerosol distribution. As a result the Angström exponent of the aerosol increases. The Angström exponent is very sensitive for changes in relative humidity during cloud evaporation, especially between $90 \%$ and $100 \%$. In addition, kinetic limitations delay evaporation of relatively large cloud drops, especially in clean and mildly polluted environments where the coarse mode fraction is relatively large. This hampers a direct relation between the aerosol optical thickness, the Angström exponent and the ambient relative humidity, which may severely complicate interpretation of these parameters in terms of aerosol properties, such as the fine mode fraction.
\end{abstract}

\section{Introduction}

Anthropogenic emissions of primary aerosol particles and aerosol precursors (sulfur dioxide, non-methane higher hydrocarbons, nitrogen oxides, soot) have increased atmospheric aerosol concentrations substantially since preindustrial times (e.g., Charlson et al., 1992; Solomon et al., 2007). Aerosols act as cloud condensation nuclei, and the increasing aerosol abundance and changing chemical composition affect climate through the so-called aerosol indirect effects. In the first indirect effect, an increase of aerosol

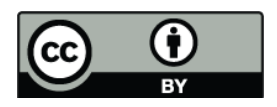

Correspondence to: G.-J. Roelofs (g.j.h.roelofs@uu.nl) particles leads to a higher cloud droplet number concentration, a smaller average drop radius and a larger optical thickness (Twomey, 1974). In the second indirect effect, the efficiency of precipitation formation decreases because of the smaller drop size, and the cloud lifetime increases (Albrecht, 1989).

To estimate the magnitude of the radiative forcing due to aerosol indirect effects, global models that simulate activation of aerosol to cloud droplets can be applied (Lohmann et al., 2007; Penner et al., 2006). Due to the complexity of the interactions between aerosol and clouds, involving large variabilities in size, chemical composition and hygroscopicity of particles, current model estimates of the aerosol indirect forcing display a large range, between approximately -0.5 and $-1.5 \mathrm{~W} \mathrm{~m}^{-2}$ (Forster et al., 2007). Analysis of aerosol properties retrieved from satellite measurements may help to decrease current uncertainties in aerosol burden and global distribution (e.g., Kaufman et al., 2002). Retrieved aerosol optical thickness gives an indication of the aerosol column burden. The Angström exponent can be used to estimate the fine fraction of the aerosol which is often associated with the anthropogenic contribution (Kaufman et al., 2005; Anderson et al., 2005; Schuster et al., 2006). The Angström exponent reflects the spectral dependence of the extinction by particles, and can be calculated from the optical thicknesses at two different wavelengths. Typical observed values of the Angström exponent are $\sim 0.15$ for desert dust and 1.77 for aerosol from urban and industrial pollution and from biomass burning (Pace et al., 2006).

Through combination with observed cloud properties (effective cloud drop radius; fractional cloud cover) the nature and magnitude of the aerosol indirect effects can be examined (Nakajima et al., 2001; Bréon et al., 2002; Myhre et al., 2007; Quaas et al., 2008). Remarkably, the radiative forcing associated with the first indirect effect estimated from remote sensing measurements appears to be relatively small, $\sim 0.2 \mathrm{~W} \mathrm{~m}^{-2}$ (Quaas et al., 2008), compared to model

Published by Copernicus Publications on behalf of the European Geosciences Union. 
derived estimates. This is consistent with other studies that found a weaker relation between aerosol and cloud optical thicknesses when derived from satellites than from models (Menon et al., 2008; Lohmann and Lesins, 2002). It is likely that part of the discrepancy is caused by an underestimation in models of the influence of natural aerosol on clouds, e.g., associated with marine organic aerosol (Roelofs, 2007). Another reason is that the observed optical thickness in the vicinity of clouds is influenced by blueing of aerosol by Rayleigh scattering (Wen et al., 2007). A third reason, connected with the present study, is the difficulty to distinguish between cloudy and cloudless air. For full consistency, aerosol and cloud properties should be retrieved from the same location. Since this is not possible, cloudy and cloudfree pixels located relatively close to another are used, under the assumption that they reflect similar conditions. Charlson et al. (2007) find that the albedo associated with cloudy conditions is not well separated from that in cloud-free environments but that a so-called "albedo continuum" exists inbetween that is associated with hydrated aerosol and wispy clouds. Similarly, cloud halos, regions of enhanced humidity in the vicinity of isolated cumulus clouds, are associated with atmospheric dynamics and reflect features of cloud formation and dissipation (Lu et al., 2003). The "twilight zone" near clouds (Koren et al., 2007) is thought of as a region of forming and evaporating cloud fragments extending many kilometers from the clouds into the cloud-free zone. The region is characterized by a decreasing aerosol optical thickness and an increasing Angström exponent with increasing distance from clouds, possibly associated with decreasing humidity, drier conditions and less water uptake by aerosol as the distance to the nearest cloud increases. Supportive of this, Loeb and Schuster (2008) calculated Angström exponents for different mixtures of fine and coarse mode aerosol and found a strong dependence on relative humidity.

Our study investigates the modification of aerosol due to cloud processes, the evolution of the aerosol size distribution caused by release of water during cloud evaporation, and the impact on aerosol optical properties. Section 2 describes the cloud parcel microphysics and chemistry model and the model initialization. In Sect. 3 we analyze the evolution of the aerosol optical thickness and the Angström exponent during cloud growth and evaporation, and we discuss how these parameters are modified by cloud processing and kinetic limitations. Aerosol populations representative of different pollution levels are examined. In Sect. 4 the conclusions and a discussion of the results are given.

\section{Model description and initialization}

The cloud parcel model simulates pseudo-adiabatic ascent of an air parcel, condensation and evaporation of water vapor on aerosols, droplet activation and condensational growth, collision and coalescence between droplets, and sulfate formation in the aqueous phase due to oxidation of dissolved sulfur dioxide by hydrogen peroxide and by ozone (Roelofs and Jongen, 2004). The initial dry aerosol size distribution is represented by 120 size bins between 0.002 and $5 \mu \mathrm{m}$ dry radius. Each bin is associated with a wet particle radius that changes upon condensation or evaporation of water. Aerosol activation, condensation and evaporation are calculated according to the Köhler equation following Hänel (1987). The Köhler equation was reformulated in terms of the solute concentrations to allow for modifications of the Raoult term by chemical processes (Roelofs, 1992). Collision/coalescence between cloud and precipitation drops is parameterized according to Jacobson (1998) and evaluated stochastically. The water and chemical contents of drops formed through coalescence of smaller droplets are transferred from the cloud drop size distribution to a separate size distribution with 50 size bins. The radii that make up this coalescence distribution are initially logarithmically distributed between 1 and $2000 \mu \mathrm{m}$, and during the simulation they are adjusted by condensation and evaporation. Further, precipitation drops are subject to removal from the parcel by gravitational settling. The model considers a time step of $0.05 \mathrm{~s}$ for the parcel ascent and the condensation and evaporation of water, while a larger time step of $2 \mathrm{~s}$ is applied for collision/coalescence and heterogeneous chemistry.

Initial aerosol size distributions are derived from three lognormal modes representing nucleation, accumulation and coarse mode aerosol, as listed in Table 1. The base case aerosol is representative for a mildly polluted marine atmosphere. Sea salt is an important component of coarse marine aerosol, but in our study we assume a similar composition as the fine mode, i.e., an internal mixture of ammonium bisulfate ( $80 \%$ volume) and unsoluble matter. Since soluble coarse mode aerosol readily activates this does not significantly influence simulated cloud characteristics. Other aerosol size distributions used in our study are adopted from Whitby (1978). The air parcel is initialized with a temperature of $288 \mathrm{~K}$ and a relative humidity $(\mathrm{RH})$ of $98 \%$. It ascends with a fixed vertical velocity of $0.2 \mathrm{~m} / \mathrm{s}$, and after the liquid water content reaches $0.4 \mathrm{~g} / \mathrm{m}^{3}$ its altitude is held constant. At $3000 \mathrm{~s}$ the parcel starts to descend with a fixed velocity of $0.2 \mathrm{~m} / \mathrm{s}$ until the simulation stops at $6000 \mathrm{~s}$. Entrainment of ambient air into the parcel is not considered.

The aerosol optical thickness of activated and interstitial aerosol particles is calculated using an approximation of the Mie scattering equation (van de Hulst, 1957), for wavelengths 533 and $855 \mathrm{~nm}$ and assuming a single scattering albedo of 1 . Total aerosol/cloud optical thickness for each wavelength is found by integrating the optical thickness for each aerosol and cloud droplet size bin over the entire size spectrum, assuming a constant air parcel thickness of $1000 \mathrm{~m}$. Finally, the Angström exponent is calculated based on wavelengths 533 and $855 \mathrm{~nm}$. We note that the refractive index of pure water, 1.33 , is assumed for all particles. Tang (1997) shows that the refractive index of solution 


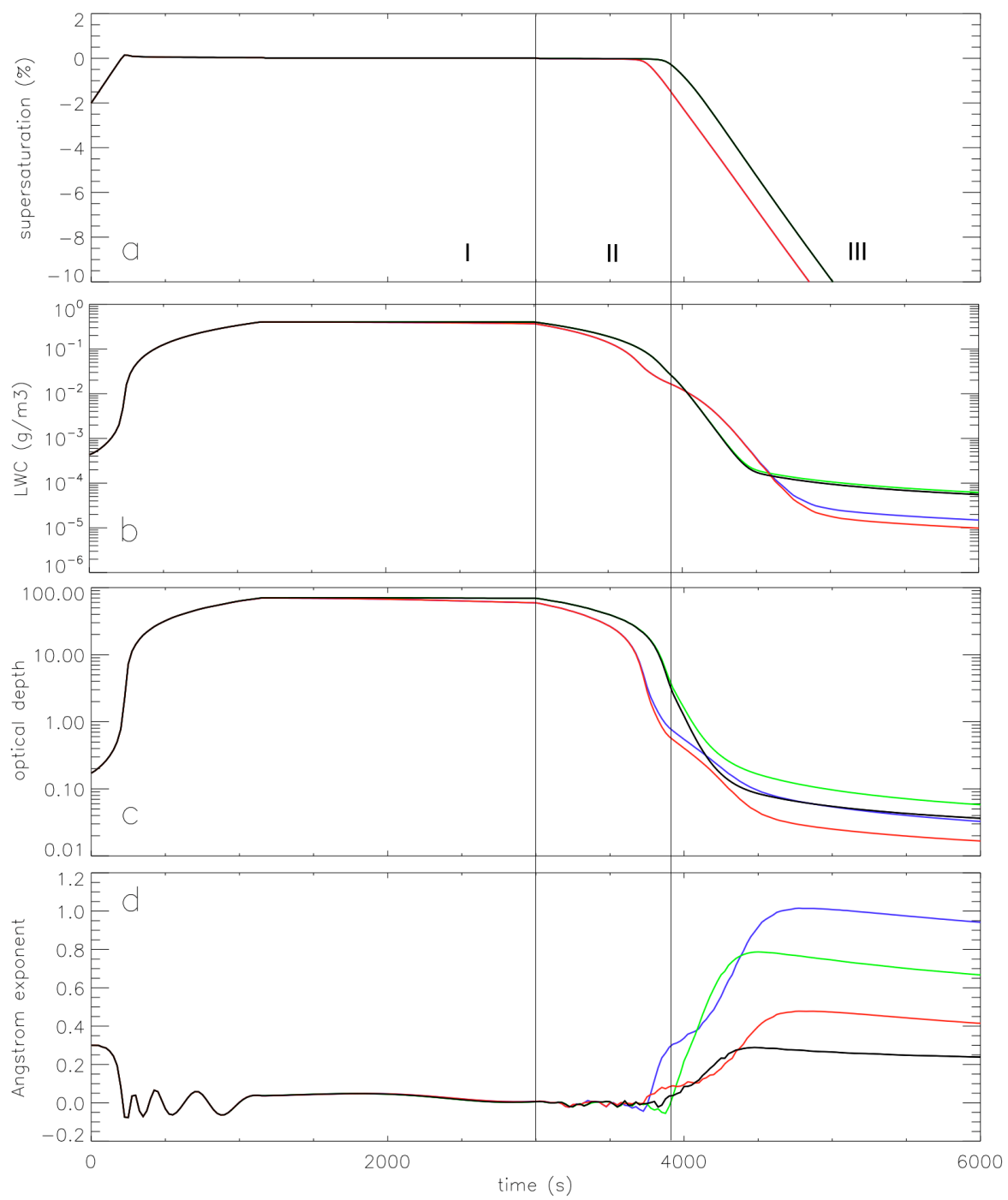

Fig. 1. (a) Simulated supersaturation, (b) liquid water content, (c) aerosol/cloud optical thickness (535 nm) and (d) Angström exponent for the simulations without cloud processing (black), with collision/coalescence (red), with aqueous phase chemistry (green), and with both collision/coalescence and aqueous phase chemistry (blue). Note that in (a) the black and green lines as well as the red and blue lines overlap. I: cloudy phase; II: cloud evaporation LWC $>0.05 \mathrm{~g} / \mathrm{m}^{3}$; III: cloud evaporation $\mathrm{LWC}<0.05 \mathrm{~g} / \mathrm{m}^{3}$.

droplets varies between 1.34 and 1.38 depending on solute concentration. The effects of these differences on the simulated optical thickness and Angström exponent are very small for these wavelengths, on the order of a few percent.

\section{Results}

\subsection{Base case}

Figure 1 shows the simulated supersaturation, liquid water content (LWC), optical thickness (OT) of the aerosol and cloud particles, and the Angström exponent $(\alpha)$ for four simulations with base case aerosol (Table 1). One simulation only considers condensation and evaporation of the aerosol and cloud droplet water, while the others also account for collision/coalescence (microphysical processing of the aerosol), or aqueous sulfate formation (chemical processing of the aerosol), or both. The parcel reaches maximum supersaturation at $\sim 200 \mathrm{~s}$, and obtains a LWC of $0.4 \mathrm{~g} / \mathrm{m}^{3}$ at $\sim 1200 \mathrm{~s}$. During descent, the supersaturation falls below 0 and remains slightly negative (upto several tenths of percent) due to the compensating influence of droplet evaporation. At $\sim 4000 \mathrm{~s}$ the LWC becomes smaller than $0.01 \mathrm{~g} / \mathrm{m}^{3}$, and after that the supersaturation steadily decreases to approximately $80 \% \mathrm{RH}$ at $6000 \mathrm{~s}$. Assuming a vertically homogeneous aerosol or cloud layer with a constant depth of $1000 \mathrm{~m}$, the calculated OT of the air parcel is 70 when the cloud is fully developed. Each simulation starts with $\alpha$ of 
Table 1. Modal parameters (number concentration $\mathrm{N}\left(\mathrm{cm}^{-3}\right)$, median radius $r(\mu \mathrm{m})$, and standard deviation $\left.\sigma\right)$ applied in the simulations. Parameters are from Whitby (1978) except for the base case. The right column shows the fine mode fraction, i.e., the dry volume fraction of aerosol particles smaller than $0.5 \mu \mathrm{m}$ radius.

\begin{tabular}{lccccccccccc}
\hline & \multicolumn{3}{c}{ Nucleation mode } & \multicolumn{4}{c}{ Accumulation mode } & \multicolumn{2}{c}{ Coarse mode } & \multicolumn{2}{c}{$V_{\text {fine }} / V$} \\
\hline & $\mathrm{N}$ & $r$ & $\sigma$ & $\mathrm{N}$ & $r$ & $\sigma$ & $\mathrm{N}$ & $r$ & $\sigma$ & \\
\hline Base case & 1600 & 0.010 & 1.7 & 400 & 0.040 & 1.9 & 10 & 0.15 & 2.8 & 0.08 \\
Marine & 340 & 0.005 & 1.6 & 60 & 0.035 & 2.0 & 3 & 0.30 & 2.7 & 0.02 \\
Clean continental & 1000 & 0.008 & 1.6 & 800 & 0.033 & 2.1 & 0.72 & 0.46 & 2.2 & 0.24 \\
Average backgr. & 6400 & 0.008 & 1.7 & 2300 & 0.038 & 2.0 & 3.2 & 0.50 & 2.2 & 0.18 \\
Aged urban plume & 6600 & 0.007 & 1.6 & 9600 & 0.060 & 1.8 & 7.2 & 0.42 & 2.1 & 0.62 \\
\hline
\end{tabular}
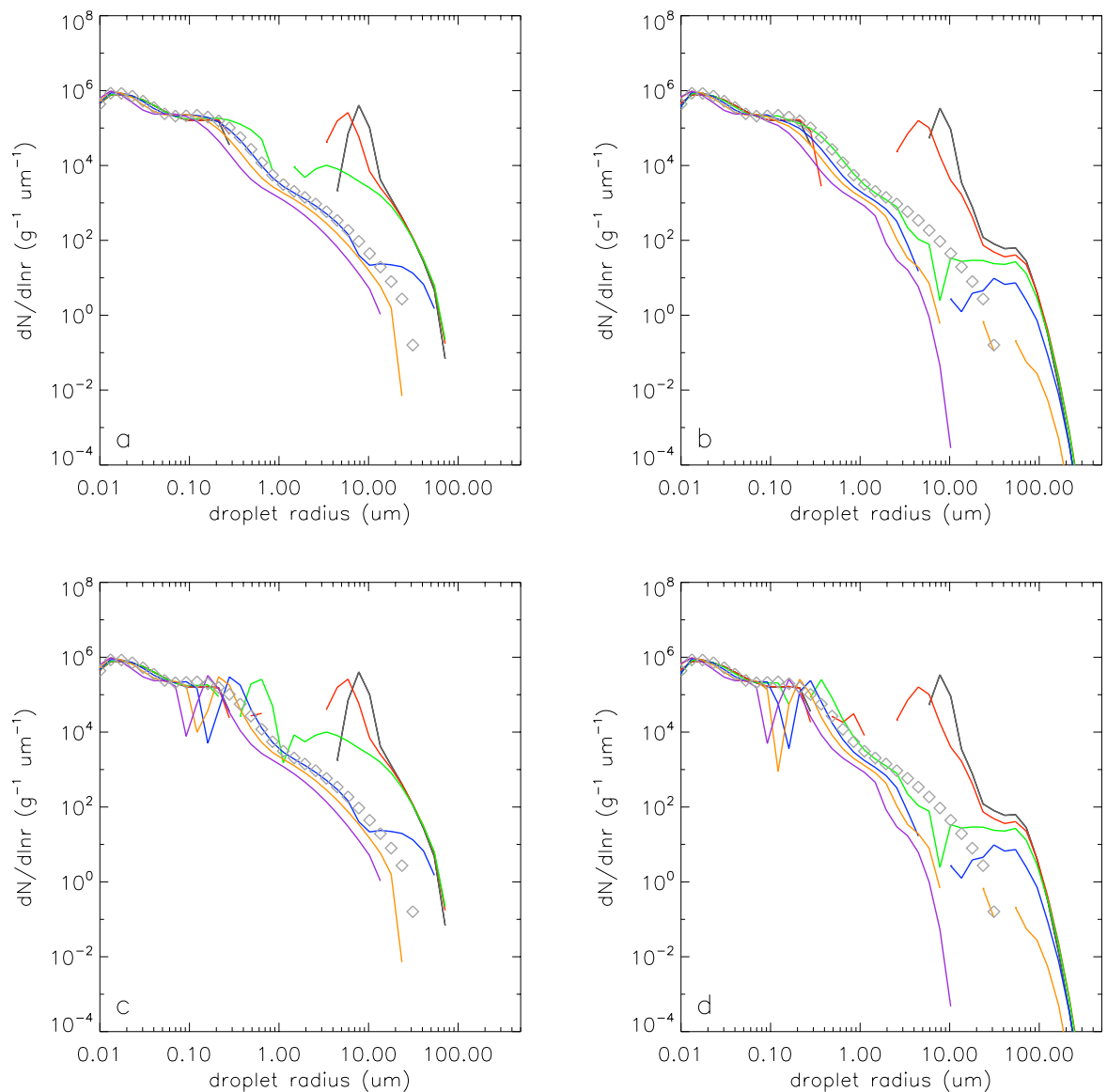

Fig. 2. Computed cloud drop size distributions during the evaporational stage of the cloud (grey dots: initial distribution; grey: 3000 s; red: $3600 \mathrm{~s}$; green: $3900 \mathrm{~s}$; blue: $4200 \mathrm{~s}$; orange: $4600 \mathrm{~s}$; purple: $6000 \mathrm{~s}$ ) for the simulations (a) without cloud processing, (b) with collision/coalescence, (c) with aqueous phase chemistry, and (d) with collision/coalescence and aqueous phase chemistry.

$\sim 0.3$. During the cloud stage $\alpha$ has values around 0 , but it increases again during cloud evaporation when the LWC drops below approximately $0.02 \mathrm{~g} / \mathrm{m}^{3}$. The increase of $\alpha$ and simultaneous decrease of OT continue until RH is $\sim 92 \%$ and the aerosol water is on the order of $10^{-4} \mathrm{~g} / \mathrm{m}^{3}$.
The results of the three other simulations show that cloud processing of the aerosol has a significant impact on OT and $\alpha$. Figures 2 and 3, displaying simulated cloud drop number and volume distributions, respectively, illustrate the microphysical evolution during cloud evaporation. At $3000 \mathrm{~s}$, when evaporation commences, the size distribution in each 

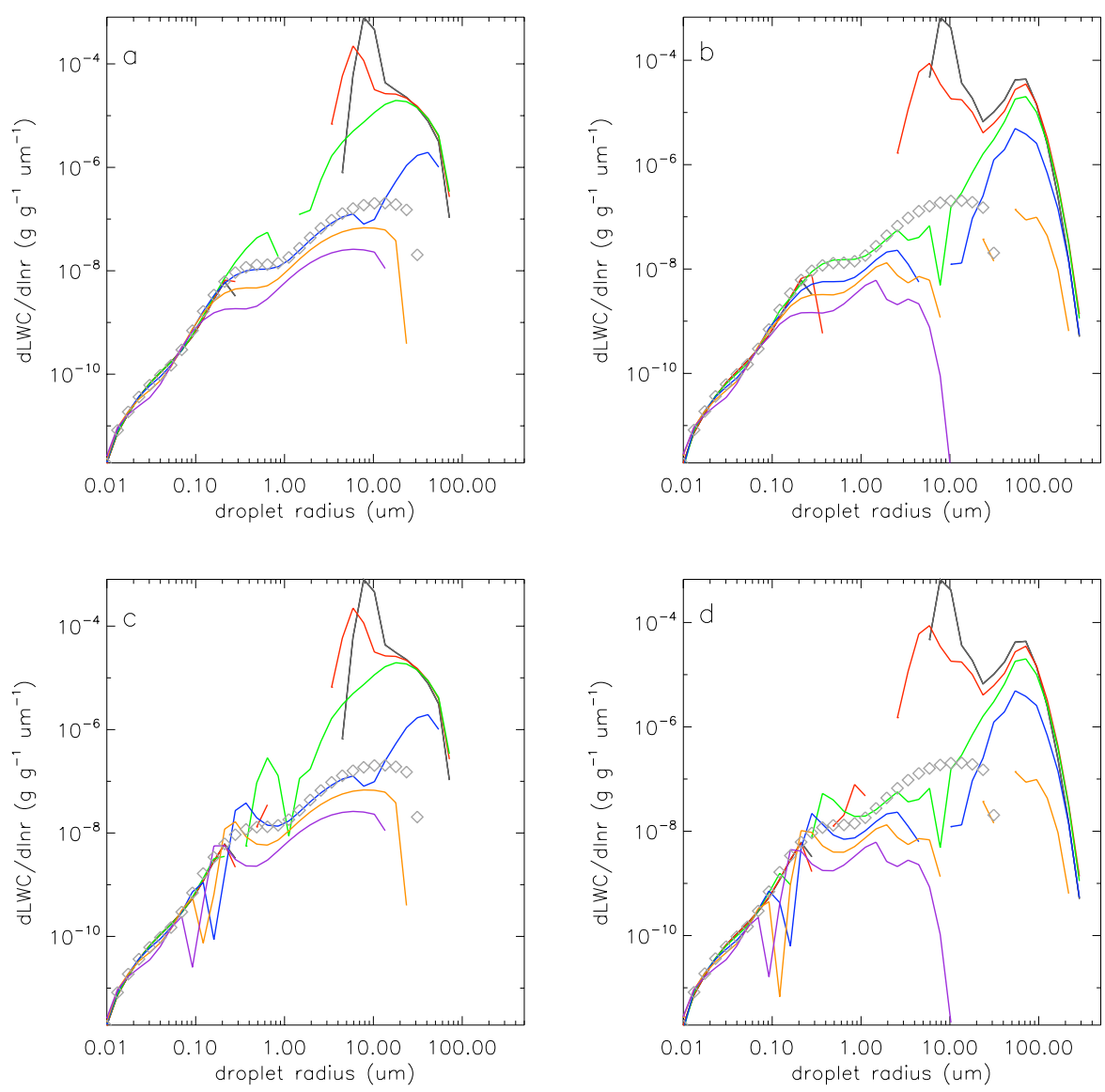

Fig. 3. As Fig. 2 but for the cloud water size distribution.

simulation displays a gap between 0.5 and $5 \mu \mathrm{m}$ that separates interstitial aerosol and activated particles. The cloud droplet concentration maximizes around $8 \mu \mathrm{m}$ radius. When the cloud evaporates the maximum shifts towards smaller sizes. At $4200 \mathrm{~s}$ the droplet spectrum in the simulation without cloud processing (Figs. 2a, 3a) is approximately the same as at the beginning of the simulation although a significant amount of droplets is still present at sizes above $20 \mu \mathrm{m}$ radius. This peak disappears between $4200 \mathrm{~s}$ and $4600 \mathrm{~s}$ when the RH is $\sim 95 \%$. In the simulation with collision/coalescence the size distribution for $3000 \mathrm{~s}$ displays a drizzle droplet peak at $\sim 80 \mu \mathrm{m}$ radius that represents $\sim 12 \%$ of the cloud liquid water. Due to fall-out of drizzle the LWC is smaller between 3000 and 4000 s than in the first simulation. During evaporation a significant number of drizzle drops persists around $80 \mu \mathrm{m}$ (Figs. 2b, 3b). Drizzle droplets are formed by collision/coalescence of smaller droplets, and the $80 \mu \mathrm{m}$ radius is close to the critical radius for activation of particles with a dry radius of $\sim 1.5 \mu \mathrm{m}$, equivalent with $\sim 18000$ coalesced accumulation mode particles. These droplets finally evaporate further after $4600 \mathrm{~s}$ when RH is below 95\%, and $\alpha$ increases again (Fig. 1d). Particle concentrations for radii exceeding $0.1 \mu \mathrm{m}$ are significantly smaller than before the cloud event, caused by the gravitational fall-out of drizzle. The contribution to the total OT from coarse mode aerosol is smaller and that from fine mode aerosol is larger than before cloud processing began. Therefore the maximum $\alpha$ is also larger, i.e., 0.5 vs. 0.3 , as shown in Fig. 1.

The chemical processing simulation is initialized with a concentration of 1 ppbv $\mathrm{SO}_{2}, 0.5 \mathrm{ppbv} \mathrm{H}_{2} \mathrm{O}_{2}$ and $30 \mathrm{ppbv} \mathrm{O}_{3}$. $\mathrm{SO}_{2}$ dissolves in the cloud water where it is chemically transformed to sulfate. This adds new aerosol matter to the droplets, especially in the smallest activated particles (Roelofs, 1992). Before cloud evaporation the simulated drop size distribution is similar to that in the base case. The in-cloud produced matter increases the Raoult (solute) effect, so that the equilibrium drop size at a given RH is larger than for unprocessed particles. The distribution for $4200 \mathrm{~s}$ shows that particles with an initial wet size around $0.2 \mu \mathrm{m}$ have grown to a somewhat larger size, $\sim 0.3 \mu \mathrm{m}$ (Figs. $2 \mathrm{c}$, $3 \mathrm{c})$. The chemical processing thus enhances the contribution of the fine mode fraction to the total optical thickness and, consequently, a larger value for $\alpha, \sim 0.7$, is calculated than before the cloud event. 

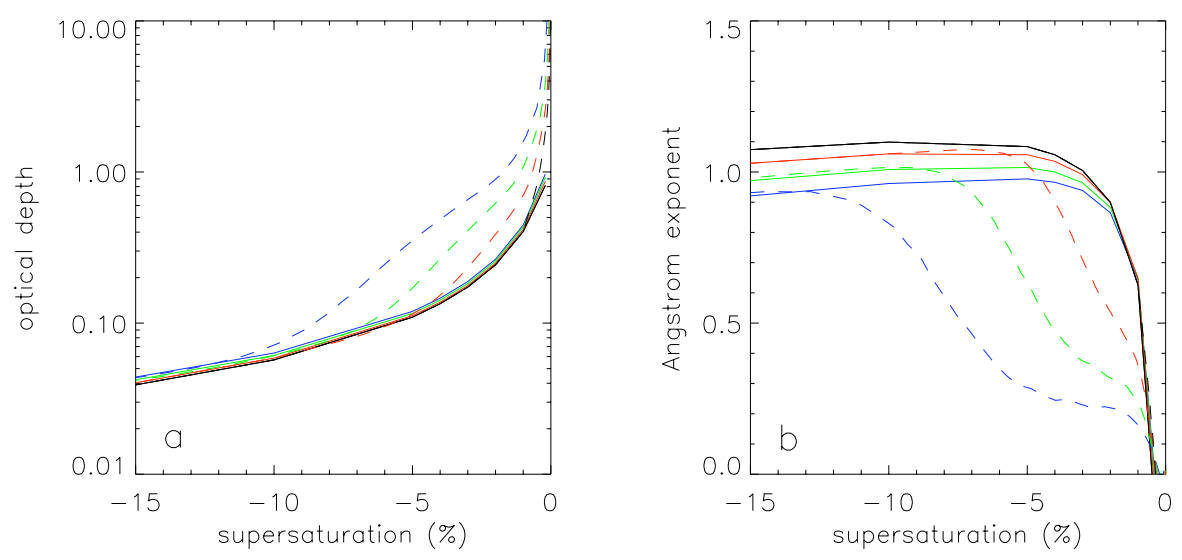

Fig. 4. Simulated (a) optical thickness $(533 \mathrm{~nm})$ and (b) Angström exponent (533 and $855 \mathrm{~nm}$ ) as function of supersaturation during cloud evaporation with downdraft velocities of $0.05 \mathrm{~m} / \mathrm{s}$ (black), $0.10 \mathrm{~m} / \mathrm{s}$ (red), $0.20 \mathrm{~m} / \mathrm{s}$ (green) and $0.40 \mathrm{~m} / \mathrm{s}$ (blue). Results obtained under assumption of full water vapor-liquid equilibrium are given by the solid lines; results considering kinetic limitations are given by the dashed lines (see text).

When microphysical and chemical processing are both considered the effects combine. The particle size distribution at the end of the simulation is steeper than in the base case, with a larger concentration of smaller and a smaller concentration of larger droplets (Figs. 2d, 3d). The impacts on OT from each processing pathway more or less cancel each other during and after cloud evaporation, so that after $\sim 4500$ s OT is similar to the base case. However, the size distribution of the remaining aerosol and the attached water are highly different, as is expressed in the corresponding value of $\alpha$ of $\sim 1$ (Fig. 1). In our study we use similar wavelengths as MODIS over the ocean (e.g., Anderson et al., 2005), whereas PARASOL and AERONET apply $440 \mathrm{~nm}$ and $670 \mathrm{~nm}$, respectively, as the shorter wavelength (see http://www-icare.univ-lille1. fr/parasol/?rubrique=aero_list; Koren et al., 2007). In our base case simulation considering full cloud processing $\alpha$ has a value of 0.968 at $\sim 96 \%$ RH and of 0.710 at $50 \%$. Using the wavelengths applied by PARASOL yields 0.975 and 0.647 , respectively, while using wavelengths applied by AERONET yields 0.969 and 0.766 , respectively. This indicates a moderate sensitivity of $\alpha$ for wavelength at RH $\sim 95 \%$ whereas at drier conditions discrepancies may be larger. For all wavelength pairs examined here, however, the simulated evolution of OT and $\alpha$ are qualitatively similar.

\subsection{Kinetic limitations}

Due to the inverse proportionality of the droplet growth rate and the droplet size (e.g., Fukuta and Walter, 1970), larger drops evaporate more slowly than small droplets. For drops containing relatively large amounts of aerosol matter, i.e., activated coarse mode aerosol but also drops formed by coalescence, the time scale of droplet growth is up to several orders of magnitude larger than the equilibrium time scale (Chuang et al., 1997). Therefore these drops do not maintain equilibrium with a rapidly changing supersaturation. Figure 4 shows the dynamically computed OT and $\alpha$ during cloud evaporation when $\mathrm{RH}<100 \%$. The four simulations consider base case aerosol and full cloud processing, but they apply different velocities for parcel descent resulting in slightly different values of $\alpha$ at the end of the simulation. Figure 4 also shows OT and $\alpha$ calculated under the assumption that the wetted aerosol size distribution is in equilibrium with the ambient supersaturation throughout cloud evaporation. Significant discrepancies between the dynamically calculated and the equilibrium OT and $\alpha$ occur for downdraft speeds exceeding $10 \mathrm{~cm} / \mathrm{s}$. The dynamically calculated OT is larger up to an order of magnitude while $\alpha$ is smaller than corresponding equilibrium values. For downward velocities smaller than $5 \mathrm{~cm} / \mathrm{s}$ the particles tend to follow their equilibrium size.

\subsection{Sensitivity studies}

Figure 5 shows the evolution of $\alpha$ as function of RH during cloud evaporation for different experiments, assuming equilibrium between aerosol water uptake and RH. Figure 5a shows the results for the base case simulation (consistent with Fig. 1d), while the other graphs reflect different cloud processing efficiencies. A larger initial $\mathrm{SO}_{2}$ concentration results in larger growth of individual particles due to in-cloud chemistry, and $\alpha$ increases more (Fig. 5b). When only $\mathrm{HNO}_{3}$ is present, which is known to have an influence on aerosol activation through the solute effect (Roelofs and Jongen, 2004; Kulmala et al., 1993), the computed $\alpha$ is almost the same as in the simulation without cloud processing because the dissolved $\mathrm{HNO}_{3}$ is released again when droplets evaporate. Figure $5 \mathrm{c}$ shows that a larger LWC during the cloudy stage results in a larger increase of $\alpha$ (Fig. 5c). This is due to more efficient collision/coalescence, aqueous phase chemistry, and aerosol removal by rain, all associated with the larger cloud drop sizes. 

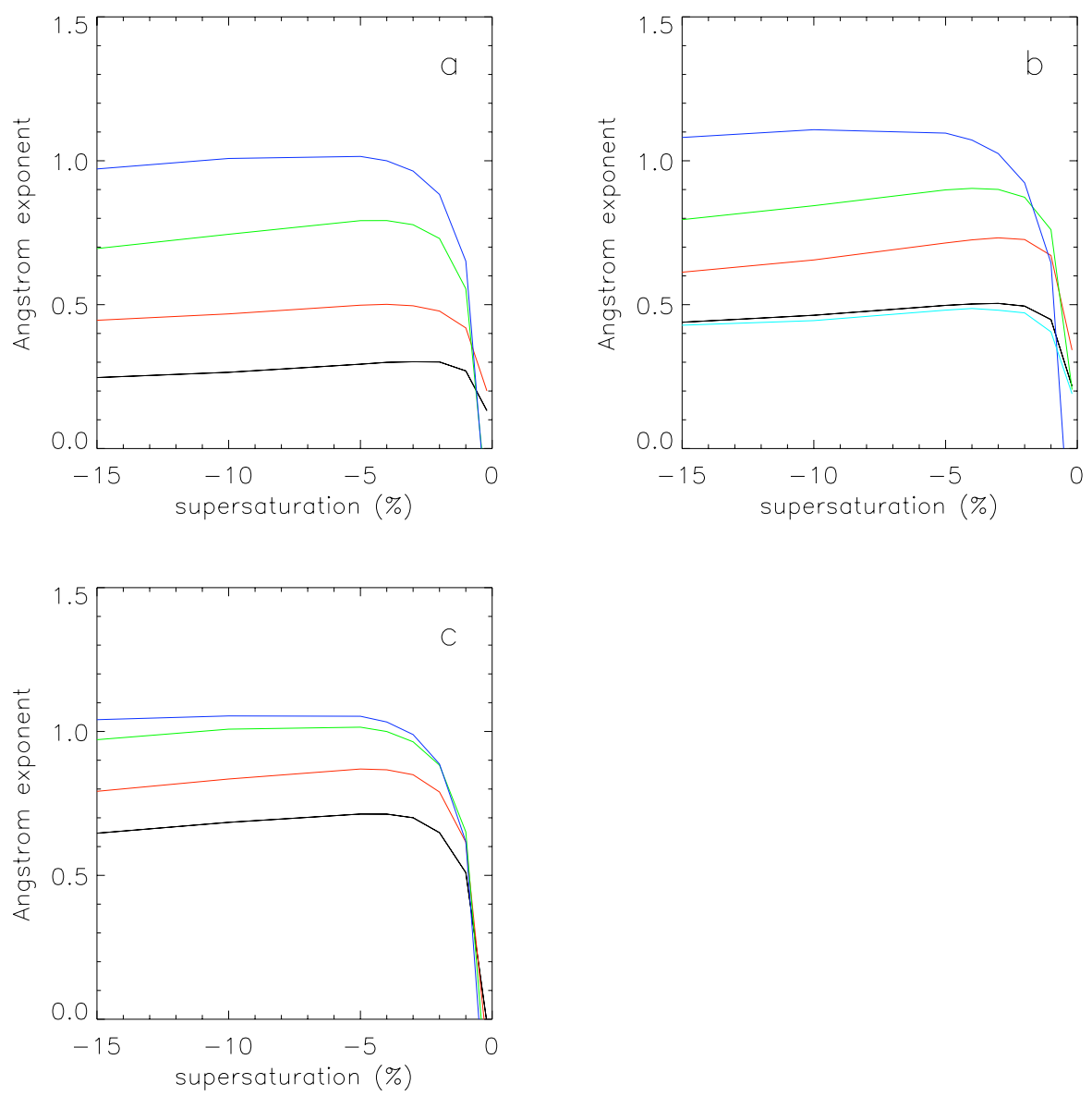

Fig. 5. Computed Angström exponent $\alpha$ (equilibrated with respect to RH) as function of RH during cloud evaporation. (a) Base case, colors as in Fig. 1d; (b) with initial $\mathrm{SO}_{2}$ of 0 ppbv (black), $0.2 \mathrm{ppbv}$ (red), $0.5 \mathrm{ppbv}$ (green) and 2.0 ppbv (dark blue); with 0 ppbv $\mathrm{SO}_{2}$ and 1 ppbv $\mathrm{HNO}_{3}$ (light blue); (c) using a cloud LWC of 0.1 (black), 0.2 (red), 0.4 (green) and $0.6 \mathrm{~g} \mathrm{~m}^{-3}$ (dark blue).

We also carried out simulations initialized with aerosol representative of clean marine, clean continental, average background and aged urban plume conditions, as defined in Table 1. The marine aerosol is assumed to consist of sea salt, and in the other cases the same chemical composition as in the base case is assumed. The results are shown in Fig. 6 . Figure 6a presents simulation results with and without considering cloud processing. It shows that the increase of $\alpha$ as a result of cloud processing is most efficient in clean atmospheres and least efficient in polluted environments. Figure $6 \mathrm{a}$ also shows, for the simulations without cloud processing, that $\alpha$ shows a weak maximum at $\sim 95 \% \mathrm{RH}$ for marine and clean continental aerosol, as in our base case simulation, whereas for aerosol representative of more polluted environments $\alpha$ increases sharply between $100 \%$ and $95 \% \mathrm{RH}$ and less sharply for RH below $95 \%$. Our calculations are consistent with Loeb and Schuster (2008; their Fig. 6) who examined the dependence of $\alpha$ on RH for different fine mode volume fractions. The results from the aged urban aerosol simulation are consistent with the AERONET data presented by Koren et al. (2007; Figs. 3 and 4) that reflect the relatively polluted conditions influenced by biomass burning. Their observations of $\alpha(\sim 1.2, \sim 1.5)$ are in good agreement with the computed $\alpha$ at $85 \%$ RH. We note that the observations in Koren et al. (2007) do not reflect the transition from cloudy conditions, where $\alpha$ is around 0 , to the twilight zone.

Figure $6 \mathrm{~b}$ and $\mathrm{c}$ show the effects of kinetic limitations on OT and $\alpha$ for a downdraft velocity of $0.2 \mathrm{~m} / \mathrm{s}$, similar as in Fig. 4, for the simulations considering only condensation and evaporation. As discussed earlier, kinetic limitations mainly affect droplets growing on coarse mode aerosol (Figs. 2, 3). Kinetic limitations appear to be less important for highly polluted conditions where the coarse mode fraction contributes relatively little to the optical depth, but they may exert a large influence in clean and moderately polluted environments. 

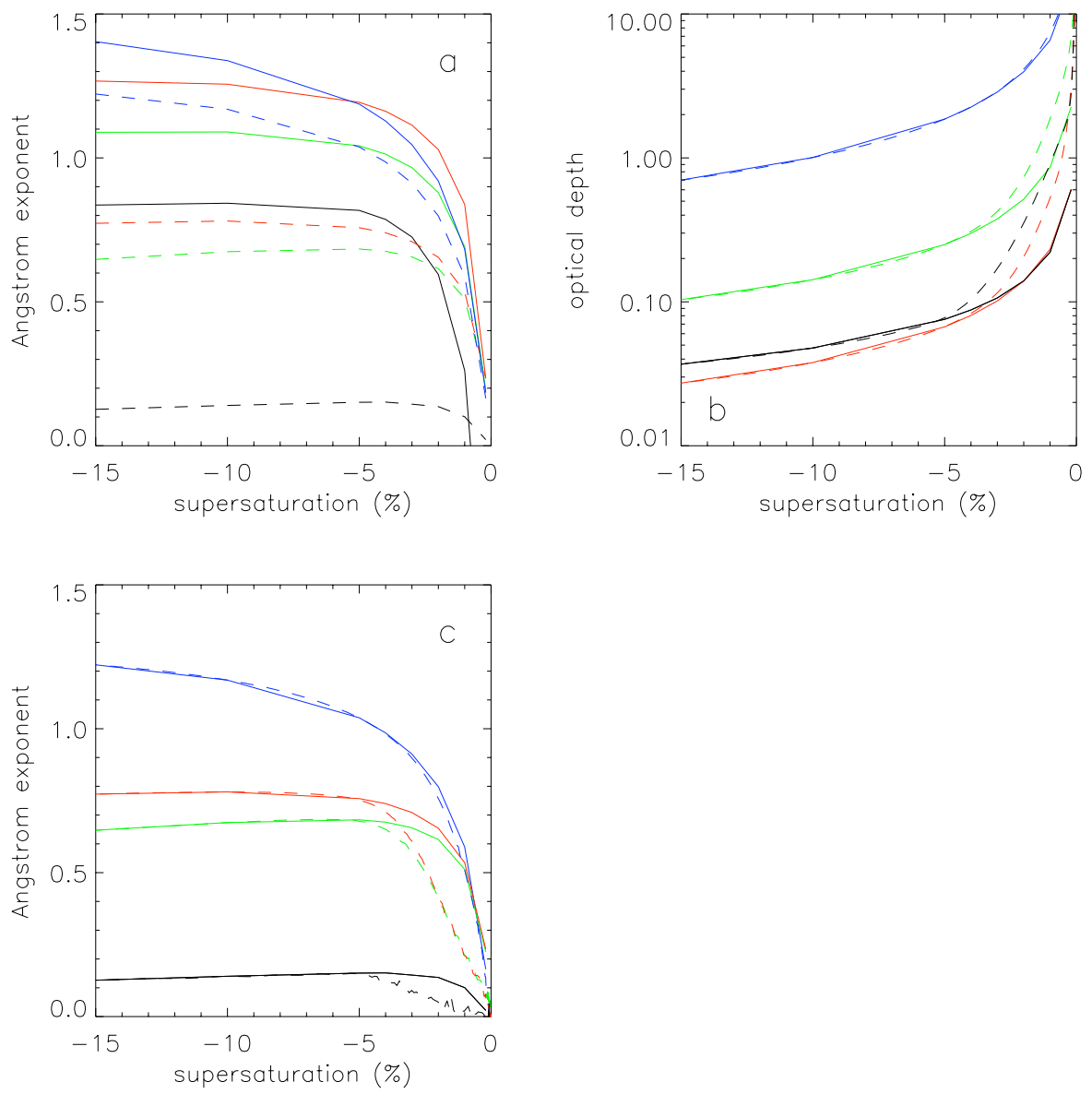

Fig. 6. (a) Computed Angström exponent $\alpha$ (equilibrated with respect to $\mathrm{RH}$ ) as function of $\mathrm{RH}$ during cloud evaporation for aerosol representative of marine (black), clean continental (red), average background (green) and aged urban plume (dark blue) conditions. Dashed lines: for simulations considering only condensation/evaporation; solid: for simulations considering full cloud processing; (b) Simulated optical thickness $(533 \mathrm{~nm})$ and (c) Angström exponent $(533$ and $855 \mathrm{~nm})$ as function of supersaturation during cloud evaporation. Solid lines: assuming water vapor-liquid equilibrium; dashed lines: considering kinetic limitations.

\section{Discussion and conclusions}

With a cloud parcel model we investigated how the size distribution and Angström exponent ( $\alpha$ based on wavelengths 533 and $855 \mathrm{~nm}$ ) of an aerosol population are modified by cloud processing and cloud evaporation. Two ways of cloud processing are considered, i.e., chemical processing through aqueous phase sulfate formation and microphysical processing through collision/coalescence.

Our simulations show that the effect of microphysical and chemical cloud processing is to sharpen the decrease of particle concentrations with increasing particle size. Consequently, the contribution of the fine modes to the aerosol OT increases, and the $\alpha$ increases. The modification appears to be stronger for aerosol representative of relatively clean (marine) conditions than for more polluted conditions when the initial $\alpha$ of the aerosol is already relatively large and drizzle formation is less efficient. The LWC of the cloud and the at- mospheric abundances of aerosol precursors that partake in in-cloud aerosol production, such as $\mathrm{SO}_{2}$, are important parameters that influence the increase of $\alpha$.

The $\alpha$ is found to be highly sensitive for RH in the range $90 \%<\mathrm{RH}<100 \%$ and for $\mathrm{LWC}<\sim 0.05 \mathrm{~g} / \mathrm{kg}$. The sensitivity is associated with different strengths of the Raoult (solute) effect for small and large aerosol particles. This means that accurate knowledge of the distribution of $\mathrm{RH}$ near clouds is required for accurate determination of the aerosol fine mode fraction (Charlson et al., 2007). Assuming vapor-liquid equilibrium for all aerosol sizes, in our base case and marine simulations $\alpha$ displays a clear maximum at $\sim 95 \% \mathrm{RH}$. In more polluted environments, however, $\alpha$ increases at least down to $85 \%$ RH. Our simulation results suggest that kinetic limitations play a significant role in most clean and polluted environments except for typical urban pollution when coarse mode fractions are relatively small. 
Kinetic limitations delay the evaporation of cloud drops so that they are larger than their equilibrium size at ambient RH. Activated coarse mode particles and droplets formed by collision/coalescence, in our base case simulation between $50 \mu \mathrm{m}$ and $100 \mu \mathrm{m}$ radius, are mostly affected. Their size decreases only very slowly during cloud evaporation, and becomes efficient only when the RH falls below 95\%. With kinetic limitations, the maximum $\alpha$ in the base case shifts towards smaller RH, between $85 \%$ and $92 \%$, depending on the downdraft speed.

This behaviour may directly relate to the "twilight zone" described by Koren et al. (2007), in the sense that the twilight zone consists of former cloud air, either a remnant from cloud evaporation or from air detrained from cumulus (Lu et al., 2003), that contains cloud and drizzle droplets that gradually evaporate in adjustment to the ambient negative supersaturation. The time scale for this as suggested by our model simulations is between 20 and 30 min depending on downdraft velocity. This is of the same order as the time scale for the variations in OT and $\alpha$ found by Koren et al. (2007).

How does this affect the interpretation of retrieved OT and $\alpha$ ? Figure 4 suggests that when the effect of kinetic limitations is significant, the actual OT is larger than its equilibrium value for the ambient RH. When this is not accounted for, the interpretation of the retrieved OT may result in an overestimation of total aerosol mass compared to the actual value. The $\alpha$ is smaller than its equilibrium value, and this may lead to an underestimation of the aerosol fine mode fraction. We note that this is consistent with Lesins and Lohmann (2006) who found that aerosol fine mode fractions in model simulations are larger than in satellite observations. In aerosol indirect effect studies aerosol and cloud parameters are directly compared. However, the retrieved aerosol may already have been processed in a cloud event so that aerosol optical thickness and Angström exponent are no longer consistent with the associated retrieved cloud effective radius. We showed that the associated aerosol optical thickness may decrease or increase depending on the nature of the processing, i.e., microphysical or chemical, while the Angström exponent becomes larger. The combined influences introduce rather complex uncertainties in the interpretation of aerosol optical parameters, but their impact appears to be larger for clean and moderately polluted environments than for highly polluted air.

Our results are relevant for studies of aerosol retrieval from satellite observations and from surface remote sensing. An accurate interpretation of the measured optical thickness and Angström exponent in terms of aerosol mass and fine/coarse mode fractions is direly needed, for example, to constrain emission inventories and reduce uncertainties in estimates of the aerosol direct and indirect effects. Our study demonstrates that aerosol-humidity and aerosol-cloud interactions complicate the interpretation. Detailed study of aerosol optical thickness and Angström exponent from satellite retrievals and comparison with results from global climate models and from detailed cloud microphysical models are needed to better quantify aerosol-water interactions in the atmosphere and account for them aerosol retrieval from remotely sensed optical parameters.

Acknowledgements. The authors wish to thank Gregory L. Schuster and an anonymous reviewer for their helpful questions and comments.

Edited by: J. Quaas

\section{References}

Albrecht, B. A.: Aerosols, cloud microphysics and fractional cloudiness, Science, 245, 1227-1230, 1989.

Anderson, T. L., Wu, Y., Chu, D. A., Schmid, B., Redemann, J., and Dubovik, O.: Testing the MODIS satellite retrieval of aerosol fine-mode fraction, J. Geophys. Res., 110, D18204, doi:10.1029/2005JD005978, 2005.

Bréon, F. M., Tanré, D., and Generoso, S.: Aerosol effects on cloud droplet size monitored from satellite, Science, 295, 834-838, 2002.

Charlson, R. J., Schwarz, S. E., Hales, J. M., Cess, R. D., Coakley, J. A., Hansen Jr., J. E., and Hofmann, D. J.: Climate forcing by anthropogenic aerosols, Science, 255, 423-430, 1992.

Charlson, R. J., Ackerman, A. S., Bender, F. A. M., Anderson, T. L., and Liu, Z.: On the climate forcing consequences of the albedo continuum between cloudy and clear air, Tellus, 59, 715-727, 2007.

Chuang, P. Y., Charlson, R. J., and Seinfeld, J. H.: Kinetic limitations on droplet formation in clouds, Nature, 390, 594-596, 1997.

Forster, P., Ramaswamy, V., Artaxo, P., Berntsen, T., Betts, R., Fahey, D. W., Haywood, J., Lean, J., Lowe, D. C., Myhre, G., Nganga, J., Prinn, R., Raga, G., M., Schulz, and van Dorland, R.: Changes in Atmospheric Constituents and in Radiative Forcing, in: Climate Change 2007: The Physical Science Basis. Contribution of WG I to the Fourth Assessment Report of the Intergovernmental Panel on Climate Change, edited by: Solomon, S., Qin, D., Manning, M., Chen, Z., Marquis, M., Averyt, K. B., Tignor, M., and Miller, H. L., Cambridge University Press, Cambridge, United Kingdom and New York, NY, USA, 2007.

Fukuta, N. and Walter, N. A.: Kinetics of hydrometeor growth from a vapor spherical model, J. Atmos. Sci., 27, 1160-1172, 1970.

Hänel, G.: The role of aerosol properties during the condensational stage of cloud: a reinvestigation of numerics and microphysics, Beitr. Phys. Atmosph., 60, 321-339, 1987.

Jacobson, M. Z.: Fundamentals of atmospheric modeling, Cambridge University Press, New York, 426-452, 1998.

Kaufman, Y. J., Tanré, D., and Boucher, O.: A satellite view of aerosols in the climate system, Nature, 419, 215-223, 2002.

Kaufman, Y. J., Boucher, O., Tanré, D., Chin, M., Remer, L. A., and Takemura, T.: Aerosol anthropogenic component estimated from satellite data, Geophys. Res. Lett., 32, L17804, doi:10.1029/2005GL023125, 2005.

Koren, I., Remer, L. A., Kaufman, Y. J., Rudich, Y., and Vanderlei Martins, J.: On the twilight zone between clouds and aerosols, 
Geophys. Res. Lett., 34, L08805, doi:10.1029/2007GL029253, 2007.

Kulmala, M., Laaksonen, A., Korhonen, P., Ahonen, T., and Baret, J.: The effect of atmospheric nitric acid vapor on cloud condensation nucleus activation, J. Geophys. Res., 98, 22949-22958, 1993.

Lesins, G. and Lohmann, U.: Using MODIS and AERONET to determine GCM aerosol size, J. Atmos. Sci., 63, 1338-1347, 2006.

Loeb, N. G. and Schuster, G. L.: An observational study of the relationship between cloud, aerosol and meteorology in broken low- level cloud conditions, J. Geophys. Res., 113, D14214, doi:10.1029/2007JD009763, 2008.

Lohmann, U. and Lesins, G.: Stronger constraints on the anthropogenic indirect aerosol effect, Science, 298, 1012-1015, 2002.

Lohmann, U., Quaas, J., Kinne, S., and Feichter, J.: Different approaches for constraining global climate models of the anthropogenic indirect aerosol effect, Bull. Am. Meteorol. Soc., 88, 243-249, doi:10.1175/BAMS-88-2-243, 2007.

Lu, M. L., Wang, J., Freedman, A., Jonsson, H. H., Flagan, R. C., McClatchey, R. A., and Seinfeld, J. H.: Analysis of humidity halos around trade wind cumulus clouds, J. Atmos. Sci., 60, 10411059, 2003.

Menon, S., Del Genio, A. D., Kaufman, Y., Bennartz, R., Koch, D., Loeb, N., and Orlikowski, D.: Analyzing signatures of aerosolcloud interactions from satellite retrievals and the GISS GCM to constrain the aerosol indirect effect, J. Geophys. Res., 113, D14S22, doi:10.1029/2007JD009442, 2008.

G., Stordal, F., Johnsrud, M., Kaufman, Y. J., Rosenfeld, D., Storelvmo, T., Kristjansson, J. E., Berntsen, T. K., Myhre, A., and Isaksen, I. S. A.: Aerosol-cloud interaction inferred from MODIS satellite data and global aerosol models, Atmos. Chem. Phys., 7, 3081-3101, 2007, http://www.atmos-chem-phys.net/7/3081/2007/.

Nakajima, T., Higurashi, A., Kawamoto, K., and Penner, J. E.: A possible correlation between satellite-derived cloud and aerosol microphysical parameters, Geophys. Res. Lett., 28, 1171-1174, 2001.

Pace, G., di Sarra, A., Meloni, D., Piacentino, S., and Chamard, P.: Aerosol optical properties at Lampedusa (Central Mediterranean). 1. Influence of transport and identification of different aerosol types, Atmos. Chem. Phys., 6, 697-713, 2006, http://www.atmos-chem-phys.net/6/697/2006/.
Penner, J. E., Quaas, J., Storelvmo, T., Takemura, T., Boucher, O., Guo, H., Kirkevåg, A., Kristjánsson, J. E., and Seland, Ø.: Model intercomparison of indirect aerosol effects, Atmos. Chem. Phys., 6, 3391-3405, 2006, http://www.atmos-chem-phys.net/6/3391/2006/.

Quaas, J., Boucher, O., Bellouin, N., and Kinne, S.: Satellite-based estimate of the direct and indirect aerosol climate forcing, J. Geophys. Res., 113, D05204, doi:10.1029/2007JD008962, 2008.

Roelofs, G. J.: On the drop and aerosol size dependence of aqueous sulfate formation in a continental cumulus cloud, Atmos. Environ., 26A, 2309-2321, 1992.

Roelofs, G. J. and Jongen, S.: A model study of the influence of aerosol size and chemical properties on precipitation formation in warm clouds, J. Geophys. Res., 109, D22201, doi:10.1029/2004JD004779, 2004.

Roelofs, G. J.: A GCM study of organic matter in marine aerosol and its potential contribution to cloud drop activation, Atmos. Chem. Phys., 8, 709-719, 2008, http://www.atmos-chem-phys.net/8/709/2008/.

Schuster, G. L., Dubovik, O., and Holben, B. N.: Angström exponent and bimodal aerosol size distributions, J. Geophys. Res., 111, D07207, doi:10.1029/2005JD006328, 2006.

Solomon, S., Qin, D., Manning, M., et al.: Technical Summary, in: Climate Change 2007: The Physical Science Basis. Contribution of Working Group I to the Fourth Assessment Report of the Intergovernmental Panel on Climate Change, edited by: Solomon, S., Qin, D., Manning, M., Chen, Z., Marquis, M., Averyt, K. B., Tignor, M., and Miller, H. L.: Cambridge University Press, Cambridge, United Kingdom and New York, NY, USA, 2007.

Tang, I.: Thermodynamic and optical properties of mixed-salt aerosols of atmospheric importance, J. Geophys. Res., 102, 1883-1893, 1997.

Twomey, S.: Pollution and the planetary albedo, Atmos. Environ., 8, 1251-1256, 1974.

Van de Hulst, H. C.: Light scattering by small particles, Wiley, New York, 176-178, 1957.

Wen, G., Marshak, A., Cahalan, R. F., Remer, L. A., and Kleidman, R. G.: 3D aerosol-cloud radiative interaction observed in collocated MODIS and ASTER images of cumulus cloud fields, J. Geophys. Res., 112, D13204, doi:10.1029/2006JD008267, 2007.

Whitby, K. T.: The physical characteristics of sulfur aerosols, Atmos. Environ., 12, 135-159, 1978. 